\title{
The Usual Causes of Left Ventricular Outflow Tract Obstruction Below the Aortic Valve in Normal Ventriculoarterial Connection: Review of the Physiopathology and Surgical Implications
}

\author{
M. Radermecker*, J. L. Canivet**, P. Lancellotti***, R. Limet* \\ *Department of Cardiothoracic Surgery, University of Liège, CHU du Sart-Tilman, 4000 Liège, Belgium ; \\ **Department of Intensive Care, University of Liège, CHU du Sart-Tilman, 4000 Liège, Belgium ; ***Department of \\ Cardiology, University of Liège, CHU du Sart-Tilman, 4000 Liège, Belgium.
}

Key words. Subaortic stenosis ; left ventricular outflow tract (LVOT) ; obstructive cardiomyopathy.

\begin{abstract}
Subaortic narrowing leading to left ventricular outflow tract obstruction (LVOTO) is a significant pathology that may be encountered pre- or postoperatively in both acquired or congenital cardiac disease. Through a review of the morphological features and mechanisms in the different clinical situations, the anatomic, dynamic and mixed forms of subaortic obstruction are emphasized. Knowledge of the substrate of LVOTO, its physiopathology and natural history allows to plan accordingly the surgical repair and the postoperative management.
\end{abstract}

\section{Introduction}

The obstruction of the LVOT may occur at the supravalvular, valvular or subvalvular levels. Obstruction below the aortic valve constitutes subaortic stenosis (SAS). This subaortic narrowing is an additional resistive factor in series with the aortic and arterial impedance that may dramatically influence the left ventricular performance. Subaortic stenosis may be the consequence of different lesions and physiopathological mechanisms. Beside a classical fixed subaortic stenosis where the anatomical substrate is prominent but encompassing a wide range of lesions, purely dynamic forms as seen after mitral valve repair or in the postop of aortic valve surgery as well as mixed forms such as seen in hypertrophic obstructive cardiomyopathy, must be taken into account. Owing to the implementation of echocardiography in the management and follow up of both pediatric and adult patients, the occurrence of that obstruction is fully realized and its treatment as well as its prevention are part of modern surgical management and postoperative care.

This paper is an attempt to review the most relevant conditions associated to subaortic obstruction and to emphasize the lesions, the dysfunctions and, whenever available, the natural history. Based on the authors' experience and a review of the literature, some suggestions for adequate management are proposed.

\section{Hypertrophic Cardiomyopathy (HC)}

$\mathrm{HC}$ is currently believed to be a familial disease in $55 \%$ of cases, leaving $45 \%$ as sporadic (1). This is a mono- genic autosomal dominant condition with much interand intragenic variability. Several morbid genes coding for $\beta$-myosine heavy chain (2), $\alpha$-tropomyosin, cardiac troponin, and myosin binding cardiac $c$ protein have been identified (3). Although many more genes are likely to be discovered, available knowledge suggests that this disease is basically the consequence of abnormal contractile proteins or key enzymes such as SERCA 2a. Therefore, the cardiac hypertrophy first thought to be the primary abnormality might be an adaptative response to a more profound deficiency in the contractile efficacy at the sarcomeric level. Morphologically, HC is characterized by an impressive left ventricular hypertrophy that may be diffuse, localized to the interventricular septum or the apex (4). In addition to the muscular anomaly, there is also to a variable extent an anomaly of the mitral valve and its subvalvular tension apparatus. These include narrow and small anterior leaflet, small annulus, endocardial thickening of the ventricular aspect of the anterior leaflet and often abnormal position of the papillary muscles (5). In the form characterized by high septal hypertrophy, there is frequent association with the systolic anterior motion of the mitral valve (SAM) (Fig. 1). The mechanism of the subaortic obstruction involves the conjunction of an anatomic obstacle (septal bulging) and the dynamic excursion of the anterior leaflet of the mitral valve. There are currently three physiopathological mechanisms to explain the dynamic component of the LVOT narrowing.

First, the activation of the interventricular septum during systole increases the bulging into the left ventricular outflow tract and produces flow acceleration with a 

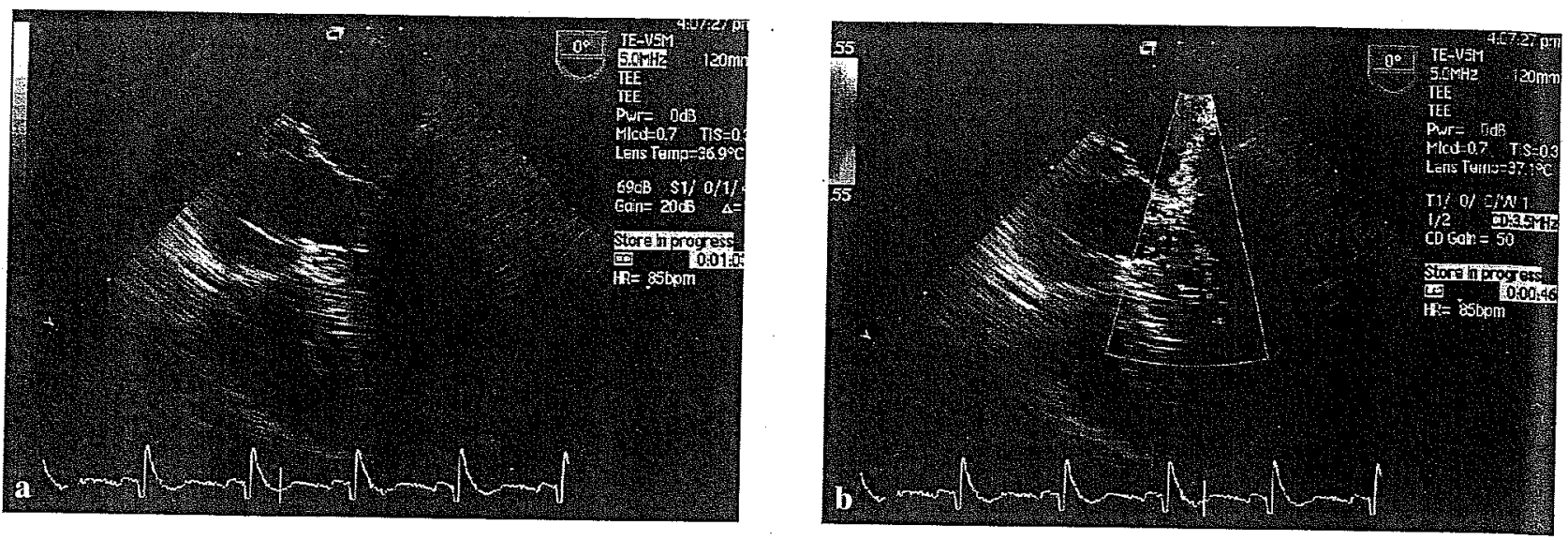

Fig. 1

LVOTO in HC (1a). Note that the SAM induces a mitraI regurgitation typically oriented opposite to the interatrial septum (1b)

reduction of the lateral pressure. This creates a Venturi effect that "attracts" the anterior leaflet of the mitral valve. This may result in the coaptation between the anterior and posterior leaflets of the mitral valve to take place in the body of the anterior leaflet and, with further anterior displacement of the anterior leaflet, a mitral valve insufficiency is produced (Fig. 1b).

The second mechanism invokes an abnormal ventricular morphology with unusual relationship of the left ventricular inflow and outflow components. A relative closure of the aortomitral angle projects the subvalvular mitral apparatus into the ventricular outflow tract. The valve and its subvalvular apparatus are pushed towards the outflow tract as soon as the pressure rises up in the left ventricular cavity and SAM is observed whilst there is no rapid flow in the LVOT. This abnormality of the LVOT and mitral valve contributes to the exposure of the leaflets to flow drag (the pushing force of flow) causing systolic anterior motion (6).

A third mechanism more recently proposed by YACOUB refers to the hinge function of the right and left fibrous trigones in the dynamic of the left outflow tract. Fibrosis in this area may tack the subaortic curtain and the anterior mitral leaflet to the muscular septum and induce the systolic anterior motion instead of a backward movement contributing to systolic enlargement of the LVOT (7). These different hypotheses are not mutually exclusive and stress the intrication of the anatomic and dynamic factors to produce the SAS.

A significant percentage of hypertrophic cardiomyopathies seen in elderly people are not genetically determined (8). In some, this hypertrophy is concentric and can be attributed to chronic hypertension (9]. It is worth to note that some forms of septal hypertrophies may be related to the development of a "sigmoid septum" and this appears to be an age related change in cardiac anatomy $(10,11)$. In particular, a sigmoid septum occurs when the take off the aorta from, the left ventricle is sharply angled instead of the relatively straight normal alignment. In this condition (steep aortoseptal angle), the basal interventricular septum bulges into the LVOT and is the substrate for LVOTO. In some patients, subaortic obstruction occurs in a context of mild to moderate hypertrophy, but huge calcifications of the posterior mitral annulus (8). This calcified annulus may displace anteriorly the posterior leaflet. Consequently the coaptation of both leaflets takes place into the body of the anterior leaflet and exposes the tip of the leaflets and subvalvular apparatus to the pushing force of flow.

Indications for surgery in patients with HOC remain a highly controversial subject. Surgery is usually considered in patients with an important gradient at rest and significant limitations not relieved by the medical treatment (calcium antagonists $\pm \beta$-blockers). Similarly indication may exist when important gradients are elicited during provocative manoeuvres, such as isoproterenol infusion, induction of ectopic beat or treadmill test. The presence of a significant mitral insufficiency is an indication for surgery. Currently, relieve of the obstruction may be obtained by the classical Morrow operation (septomyectomy) (12), extended myectomy with mobilization and partial excision of the papillary muscles (13), mitral valve replacement (14), septomyectomy + mitral valvuloplasty (Carpentier), and myectomy + mobilization of the fibrous trigones (Yacoub), and last (video assisted), port access, transmitral septal resection with patch augmentation of the anterior leaflet of the mitral valve (Vanermen, personnal communication) Dual chamber DDD pacing with short atrioventricular delay to assure complete "pace induced" ventricular depolarization reduces resting gradients by approximately $50 \%$ (15) but without overall increase in exercise time or maximal oxygen consumption (16). Percutaneous alcohol ablation of the first septal artery leads in sustained 


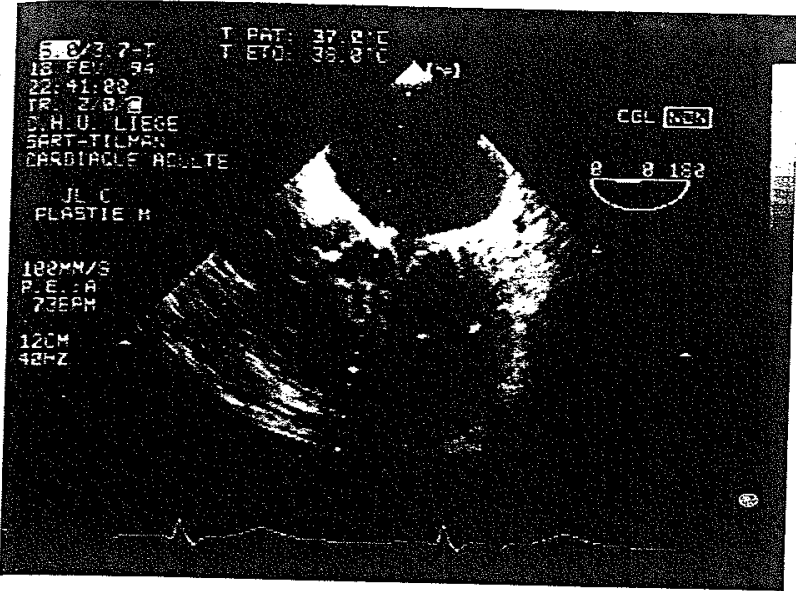

Fig. 2

Transient SAM (arrow) after mitral valve repair (ring 28 in an obese female patient with well developed posterior leaflet).

reduction in LV outflow gradients and improvement in symptoms and exercise performance (17). In the case control study of NAGUEH et al. (54), gradient reduction and symptoms relief were similar between ablation and surgical groups. Requirement for permanent pacemaker was ten fold higher in the ablation group ( $22 \%$ vs. $2 \%$ )

\section{Subaortic obstruction after mitral valve repair (SAM effect)}

The incidence of subaortic obstruction following mitral valve repair has been quoted as at least $6 \%(18,19)$. This complication has already been described after valve replacement using high profile prostheses or with newer techniques sparing the mitral valve leaflets and subvalvar apparatus $(20,21)$. The SAM is responsible for a real obstacle to the left ventricular ejection (Fig. 2) and usually accounts for postoperative low cardiac output or failure to cerne of bypass. Following the studies of Mihaileanu and Carpentier (18), the SAM after repair of the mitral valve is better understood. It appears that this condition is due to the coexistence of both non specific factors resulting from mitral surgery and specific factors related to the etiology of the mitral valve disease.

Following surgery, there is a significant reduction of the aortomitral angle (18), and a different configuration of the left ventricle. The left ventricular posterior wall is displaced anteriorly and the filling compartment of the left ventricle may become part of the subaortic region This closure of the aortomitral angle has been facilitated by left atrial dilatation and is further aggravated by a narrowing of the annulus and ring annuloplasty. There is functionally an overlapping of two distinct compartments of the LV, the filling of the left ventricle taking place in the LVOT (22) (Fig. 3 a, b).
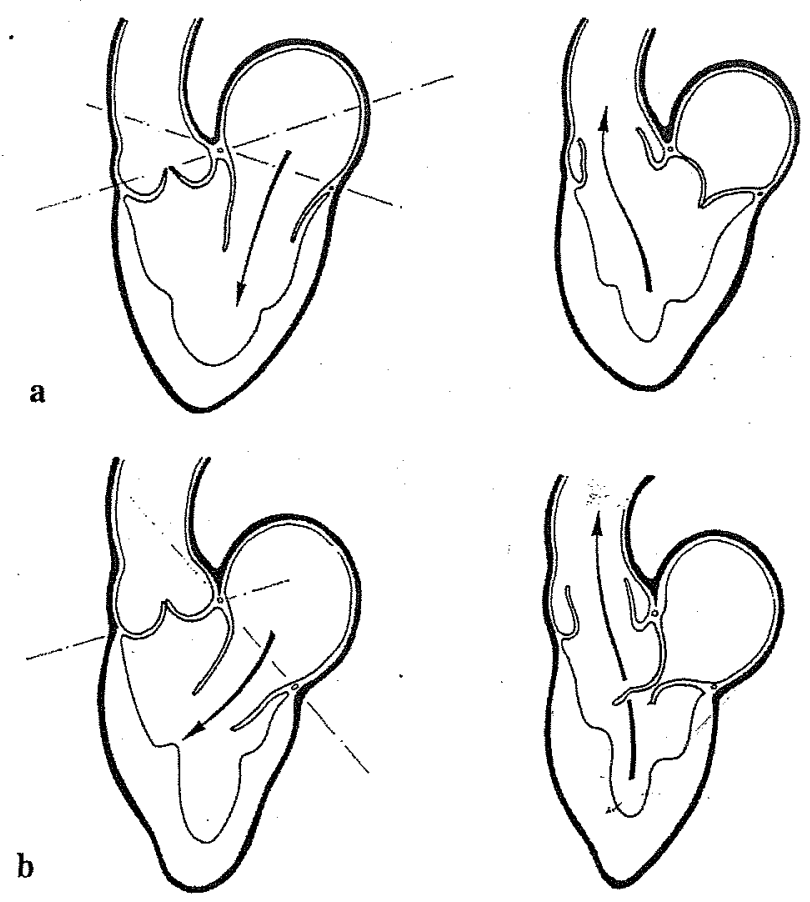

Fig. 3

Mechanism of SAM after mitral valve repair.

$-3 a$ : normal situation

$-3 b$ : schematic representation of the effects of the closure of the aortomitral angle.

The specific factors seem to be related mainly to degenerative etiologies (Barlow disease), and/or to prolapse of a very developed posterior leaflet. This specific factor allows the ventricular pressure to apply on the ventricular surface of the unusually developed posterior leaflet which will account for $75 \%$ of the occlusion of the mitral orifice, whilst the anterior leaflet will be pushed towards the septum. This is the substrate of the LVOTO via SAM septal contact, and also the mitral regurge that is associated to that condition. To prevent the SAM, surgery should aim at reducing the surface area and height of the posterior leaflet (and rarely the anterior leaflet), and placing a ring as wide as possible. A high index of suspicion in degenerative-dystrophic etiologies, particularly when the posterior leaflet is huge (as in Barlow disease) and the regular use of the sliding leaflet technique and proper ring insertion $(22,23)$ should unable surgeon to avoid this complication. If any subaortic obstruction is nevertheless observed after surgery, medical treatment including adequation of the preload, reduction of inotropic drugs, and possibly the use of negative inotropic drugs ( $\beta$-blockers), should improve the situation (24). The SAM usually disappears within six months to one year after surgery, as a result of left ventricular remodelling. 


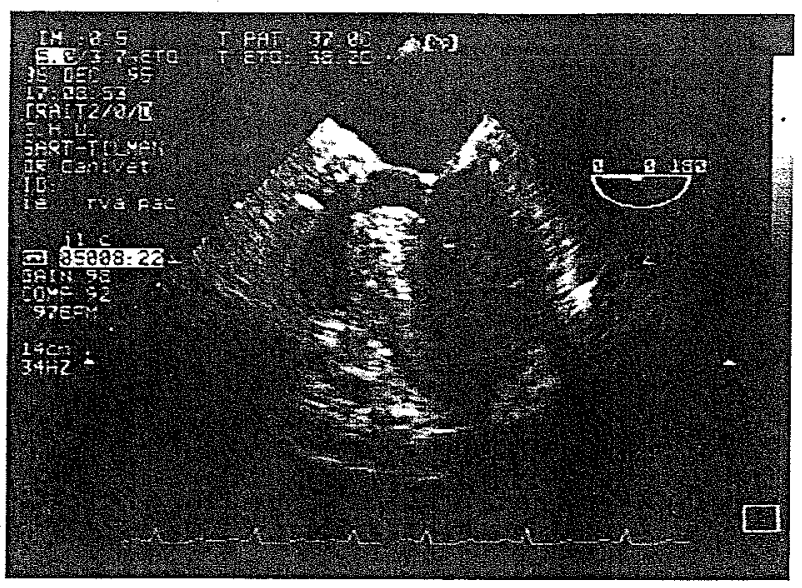

Fig. 4

Conjunction of mid-ventricular gradient and SAM after aortic valve replacement. Note the presence of a "Sigmoïd septum".

\section{3. "Mid-ventricular obstruction" and SAM after aortic surgery}

Intraventricular flow accelerations have been detected postoperatively in approximately $12 \%$ of patients undergoing aortic valve replacement, usually for critical aortic stenosis (25). Pulsed Doppler studies have shown that peak velocities were maximal at end systole and started at the level of the papillary muscles with extension towards the outflow tract (Fig. 4). Hemodynamically, this syndrome resembles hypertrophic obstructive cardiomyopathy but the systolic anterior motion of the mitral valve is less frequent suggesting a different phys. iopathological mechanism. The explanation of this syndrome invokes the acute changes following afterload relief in the setting of a hypercontractile small cavity left ventricle characterized by concentric hypertrophy and impaired diastolic function $(25,26)$. The narrowing of the left ventricular cavity has been described as mid ventricular obstruction or cavity obliteration. This syndrome which accounts for increased morbidity and mortality (27) is facilitated by hypovolemia, afterload reduction, unnecessary positive inotropic stimulation and tachycardia. It also accounts for some of the low cardiac output syndrome after aortic valve surgery. Following prompt recognition with transoesophageal echography, management should consist in cessation of inotropic stimulation, increasing volemia and if necessary the use of $\beta$-blockers. The benefits of peroperative myotomy-myectomy in high risk patients scheduled for aortic surgery are not known but seem warranted whenever septal bulging and LVOT flow acceleration are evidenced in preoperative echo.

\section{Fixed discrete subaortic stenosis}

Fixed subaortic stenosis can occur in isolate or in conjunction with other cardiac anomalies, such as

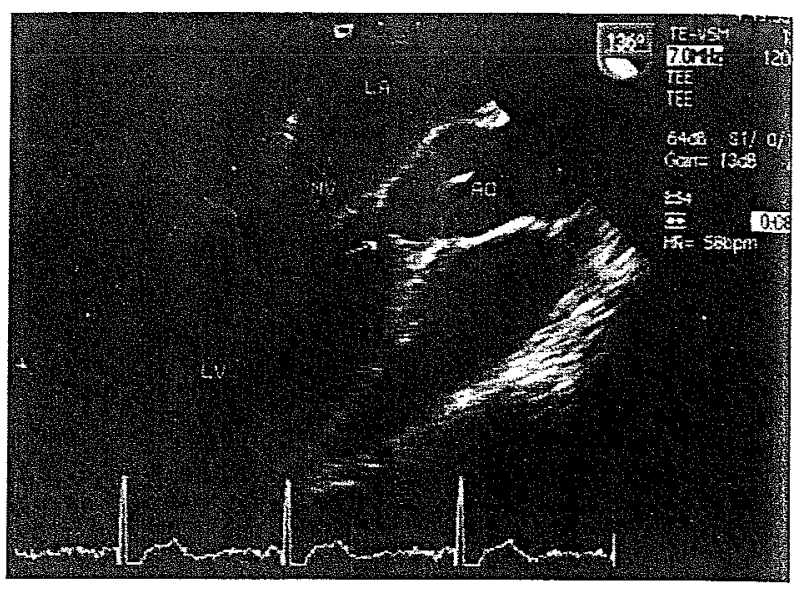

Fig: 5

Discrete subvalvular stenosis (arrow)

ventricular septal defect, patent ductus arteriosus, coarctation of the aorta, aortic stenosis, interruption of the aortic arch $(28,29)$. This lesion which accounts for 8-30\% of all forms of ventricular outflow tract obstruction may present as a crescent shape ridge of fibroelastic tissue protruding from the left septal surface to the LVOT, or as a horseshoe shelf with extension to the anterior leaflet of the mitral valve (Fig. 5). Sometimes this fibrotic subvalvular narrowing extends 10 to $30 \mathrm{~mm}$ downwards and leads to a fibromuscular narrowing of varying severity. There is clinical and experimental evidence that discrete subvalvular aortic stenosis is an acquired lesion (30). Morphologic abnormalities of the outflow tract (31), persistence of embryonic endocardial cushion tissue (32) and abnormal flow pattern have been proposed as the primum movens of subvalvular fibrous tissue proliferation $(33,34)$. Currently, this lesion is believed to be the consequence of chronic flow turbulences in the outflow tract induced by outflow tract malformation or intraventricular abnormalities. Abnormal flow dynamics in the LVOT accounts for chronic endothelial injury which, via the production of growth factors, produces the fibrotic changes. These may involve the trigones and by the suppression of their hinge function (between the subaortic curtain and the muscular septum), further aggravates the hemodynamics in the LVOT.

It is of note that outflow tracts, characterized by a wider mitral-aortic separation, an exaggerated aortic override and a steeper aortoseptal angle are present in children with VSD or coarctation of the aorta or both who subsequently develop subaortic stenosis. These morphometric features can be used to identify by echocardiography patients who are at risk for developing fixed subaortic stenosis (35). Clearly, the persistence of abnormal flow patterns when the blood flow reaches 
the subaortic area explains the recurrence of the obstruction after surgery (34).

The surgical indications for subaortic stenosis usually rely upon clinical symptoms, high resting gradients, and the development of aortic insufficiency even in mild forms. This lesion is associated to a risk of bacterial endocarditis (which is 13 to $20 \%$ ), probably as a result of chronic endothelial injury $(34,37)$.

Classically, the sharp and/or blunt resection of the membrane has been associated to a myotomy and/or a myectomy, which is believed to reduce the risk of recurrence (38). More recently, Yacoub has proposed mobilisation of the right and left trigone in association to resection of the fibromuscular ridge (7). Postulating that chronic disturbances in the outflow tract may be the primum movens of discrete subaortic stenosis, it seems logical to explore this area and the apicotrabecular component of the LV to remove any muscular band, or fibrous tractus anchored within or below the LVOT, accessory mitral valve tissue, etc. during surgery. Similarly, correction of morphological anomalies should be performed during routine VSD closure or AVSD repair. Tunnel subvalvular stenosis requires the opening of the infundibular septum via a Kono (opening of the infundibular septum, patch enlargement of this area and aortic valve replacement, reconstruction of the RVOT) or a modified Kono approach depending on the status of the aortic valve and annulus (39). An aortoseptal approach has been proposed by Voue \& Neveu. This operation combines the advantage of preserving the aortic valve (although previously transsected in the commissures between the right and left cusps whilst permitting a wide resection of the left ventricular outflow tract (40). Currently the extended Ross procedure seems to be the best option to completely relieve the hypoplastic valvar annulus and LVOTO (41).

\section{LVOTO in atrioventricular septal defect (AVSD)}

The prevalence of LVOTO in AVSD defect is quoted between $3-7 \%(42,43)$. It may constitute a serious life threatening problem after AVSD repair or valve replacement in this setting. Anatomic studies by Blieden and coworkers have demonstrated that the distance between the left AV valve and the apex (inflow distance) is much smaller than the distance between the aortic valve and the apex (outflow distance) (44). Whilst a ratio of $1 / 1$ is found in normal ventricles, it is only $0.7 / 1$ in partial AVSD. This feature alters the left ventricular geometry and results in a narrower outflow tract, facilitating subsequent subaortic obstruction. Ebels and coll. have further evidenced the longer than normal aortomitral continuity in partial AVSD (45) In addition to the fibrous extension between the aortic valve and the superior leaflet of the left AV valve, they showed the presence of an atrial fold doubling that structure cephalad and positioning the hinge of the superior leaflet more caudally than the aortic valve. This contrasts with the normal aortomitral fibrous continuity, sometimes called intervalvular septum, on which is inserted the left atrial wall. The deficiency of the interventricular septum in AVSD creates the classical "scooped out" appearance of the septal crest. When the valvular tissue is attached to the crest (partial AVSD, complete AVSD Ratelli type A), the left superior bridging leaflet follows the concavity of the "scooped out" septal crest and encroaches on the subaortic area which is already narrow. In case of complete AVSD with free floating superior bridging leaflets, the absence of attachment of this leaflet to the septal crest allows its bulging towards the atrium well away from the LVOT. These anatomic features constitute, the substrate for LVOTO in AVSD, especially in the partial form where the superior leaflet is firmly attached to the septal crest. Closure of the zone of apposition ("cleft") between the superior and inferior leaflets further reduces the mobility of this valve area and facilitates LVOTO. Associated anomalies such as bulging septum, aneurysm of the membranous septum, abnormal muscle bundle or chordae may also be obstructive after repair. If valve replacement is contemplated, the resection of part of the atrial fold below the aortic annulus should reduce the length of the ventricular outflow tract and reduce the risk of obstruction (45). Alternatively, the interposition of a Dacron or pericardial patch between the prosthesis annulus and the subaortic area has been advocated (43, 46). Subaortic obstruetion after repair of a complete AVSD is less likely if the plane of the valve reconstruction is well above the septal crest, therefore avoiding the left superior leaflet to encroach the subaortic area. Several authors have recommended left AV valve repair for subaortic obstruction in partial AVSD due to malattachment of the superior leaflet $(47,48)$. Basically, the technique utilises patch augmentation of the base of the superior leaflet at its attachment with the septal crest to lift up the superior leaflet and to widen the outflow tract. Also, subaortic fibrous shelf or thickened subvalvular apparatus probably as a result of locally turbulent flow may compound or create LVOTO obstruction. Tunnel forms have also been described in that pathology (43).

\section{Multiple levels LVOT obstruction : the spectrum of the hypoplastic left heart syndrome and the Shone complex}

Coarctation with or without PDA and hypoplasia of the distal aortic arch can coexist with lesions such as hypoplasia of the ascending aorta, supravalvular and subvalvular stenosis, hypoplasia of the left ventricle, aortic atresia, fibroelastosis, supravalvular mitral membrane or parachute mitral valve. A combination of the 
possible various associations, including the Shone syndrome (supravalvular mitral membrane, parachute deformity after mitral valve, LVOTO and coarctation), are currently considered to represent the spectrum of the hypoplastic left heart syndrome (49). Similarly, patients with interrupted aortic arch have usually number of features of the hypoplastic left heart syndrome, including posterior malalignment of the outlet septum, hypertrophy of the Moulaert's muscle, bicuspid dysplastic aortic valve, narrow annulus and hypoplasia of the ascending aorta. The occurrence of LVOTO after interrupted arch repair and perimembranous or subarterial VSD closure is $40 \%$ at six years $(49,50)$. The surgical treatment of fixed subaortic stenosis may apply in this setting. The frequent association of valvar with subvalvar stenosis is best managed by the use of the pulmonary autograft, where the LVOT is enlarged with the pulmonary infundibular muscle harvested in continuity with the pulmonary valve ("extended Ross" procedure) (41).

\section{Miscellaneous causes of LVOTO}

Other abnormalities directly or indirectly related to the components of the outflow tract such as tissue tags, membranous septum aneurysm, anomalous attachment of the mitral valve (especially in the setting of true cleft anterior leaflet) or hypertrophy of the anterolateral muscle of the LV (Moulaert's muscle) may be recognized as anatomic causes of LVOTO (51). The development of subaortic stenosis after PA banding is also a classical complication (52). Metastatic or primary cardiac tumours (myxoma, fibroelastoma...) have been recognized as unusual causative factors for LVOTO (53).

\section{Comments}

A review of subvalvular aortic stenosis in either acquired or congenital heart diseases emphasizes the importance of this issue in daily surgical practice. The aim of cardiac surgery is not only to deal with the classical anatomical causes of subaortic stenoses, but also to attempt to interfere with the occurrence of that complication in diseases such as VSD, AVSD, or avoid it in mitral valve repair or after routine aortic valve replacement.

The understanding of the physiopathology and the knowledge of its prevalence in a given cardiac pathology treated must contribute to a more efficient surgical treatment, not only in terms of immediate but also late results. Echocardiography is the key technique to demonstrate the anatomical factors and the hemodynamic aspects accounting for LVOTO. Whenever an anatomic narrowing is the main cause responsible for the augmentation of left ventricular impedance, aggressive management is warranted to completely relieve the obstruction. If the disease is acquired, then one should attempt to recognize promoting factor which may, via abnormal ventricular anatomy and flow pattern in the outflow tract, explain recurrence and to plan an operation that will lessen the risk of subsequent development of LVOTO.

The SAM effect observed after mitral valve repair is probably a paradigm to demonstrate how the understanding of the mechanism of subaortic obstruction can lead to modifications of the surgical technique, which virtually eliminates this complication.

\section{References}

1. Maron B., Nichols P., Pickle L., Wesley Y., Mulvihill J. Patterns of inheritance in hypertrophic cardiomyopathy: assessment by M-mode and 2-dimensional echocardiography. Am $J$ Cardiol, 1984, $53: 1087-1094$.

2. Geisterfer-Lowrance A., Kass S., Taanigawa G., Vosberg H. P., Mckenna W., Seidman C. E., Sempman J. G. A molecular basis for familial hypertrophic cardiomyopathy : a b cardiac myosin heavy chain gene missense mutation. Cell, 1990, 62: 999-1006.

3. Thierfelder L., Watkins H., Macrae C., Lamas R., Mckenna W. Vosberg H. P., Seidman J. G., Seidman C. E. a.Tropomyosin and cardiac troponin $T$ mutations cause familial hypertrophic cardiomyopathy : a disease of the sarcomere. Cell, 1994, $77: 701-702$.

4. Wigle E. D., Sasson Z., Henderson M. A., Rudd T. D., Fulop J., RAKOWSKI H., WILLIAMS W. G. Hypertrophic cardiomyopathy: the importance of the site and the extent of hypertrophy. A review. Prog Cardiovasc Dis, 1985, $28: 1-83$.

5. Klues G. H., Maron B. J., Dollar A. L., Roberts W. C. Diversity of structural mitral valve alterations in hypertrophic cardiomyopathy. Circulation, 1992, $85: 1651-1660$.

6. Sherrid M. V., Chu C. K., Delia E., Mogtader A., Dwyer E. M. An echocardiographic study of fluid mechanics of obstruction in hypertrophic cardiomyopathy. JACC, 1993, 3: 816-825.

7. Yacoub M., Onuzo O., Riedel B., Radley-Smith R. Mobilization of the left and right fibrous trigones for relief of severe left ventricular outflow obstruction. J Thorac Cardiovasc Surg, 1999, $117: 126-133$.

8. Lewis J. F., Maron B. J. Clinical and morphologic expression of hypertrophic cardiomyopathy in patients $\geq 65$ years of age. Am J Cardiol, 1994, 73 : 1005-1111.

9. Topol E. J., Traill T. A., Fortuin N. J. Hypertensive hypertrophic cardiomyopathy in the elderly. $N$ Engl J Med, 1985, 312: 277283.

10. Goor D., Lillehei C. W., Edwards J. E. The "sigmoid septum" variation in the contour of the left ventricular outlet. AJR Am J Roentgenol, 1969, $107: 366-376$.

11. Dalldorf F. G., Willis P. Angled aorta ("sigmoid septum") as a cause of hypertrophic subaortic stenosis. Hum Pathol, 1985, 16 : 457-462.

12. Morrow A. G. Hypertrophic subaortic stenosis. Operative methods utilized to relieve left ventricular outflow obstruction. I Thorac Cardiovasc Surg, 1978, $76: 423-430$.

13. Schoendube F. A., Klues H. G., Reith S., Flachskampf F. A., HANRATH P., Messmer B. J. Long-term clinical and echocardiographic follow-up after surgical correction of hypertrophic obstructive cardiomyopathy with extended myectomy and reconstruction of the subvalvular mitral apparatus. Circulation, 1995, 92 II : 122-127.

14. CoOley D. A., WuKasch D. C., Leachman R. D. Mitral valve replacement for idiopathic hypertrophic subaortic stenosis. $J$ Cardiovasc Surg, 1976, $17: 380-387$.

15. JeAnRENAUd X., GoY J.- J., Kappenberger L. Effects of dualchamber pacing in hypertrophic obstructive cardiomyopathy. Lancet, 1992, $339: 1318-1323$.

16. Maron B. J., Nishimura R. A., Mckenna W. J., Rakowski H., JosephSON M. E., Kieval R. S. Assessment of permanent dual- 
chamber pacing as a treatment for drug-refractory symptomatic patients with obstructive hypertrophic cardiomyopathy. A randomized, double-blind, crossover study (M-PATHY). Circulation, $1999,99: 2927-2933$

17. Faber L., Meissner A., Ziemssen P., Seggewiss H. Percutaneous transluminal septal myocardial ablation for hypertrophic obstructive cardiomyopathy : long term follow up of the first series of 25 patients. Heart, $2000,83: 326-331$

18. Mihaileanu S., Marino T., Chauvaud S., Perier P., Forman J. Viossat J., Julien J., Dreyfus G., Abastado P., Carpentier A. Left ventricular outflow obstruction after atrial valve repai (Carpentier's technique): proposed mechanism of disease. Circulation, 1988, Suppl 1, 73 (3): 78-84.

19. Grossi E. A., Galloway A. C., Parish M. A. Experience with twenty-eight cases of systolic anterior motion after mitral valve reconstruction by the Carpentier technique. $J$ Thorac Cardiovasc Surg, 1992, 103:466-470

20. Omoto T., Matsumura M., asano H., Kyo S., Takamoto S., YoKote Y., WONG M. Doppler ultrasound examination of prosthethic function and ventricular blood flow after mitral valve replacement. Herz, 1986, $11: 346-350$.

21. De Canniere D., Janssens J. J., Unger P., Leclerc T. L. Left ventricular outflow tract obstruction after mitral valve replacement. Ann Thorac Surg, 1997, 64 : 1805-1806.

22. Jebara V. A., Mrhallenu S., Acar C., Brizard C., Grare P., Latremouille Ch., Chauvaud S., Fabiani J. N., Deloche A., CARPENTIER A. Left ventricular outflow tract obstruction after mitral valve repair. Results of the sliding leaflet technique. Circulation, 1993, $88(5,2):$ 30-34.

23. Carpentuer A. The sliding leaflet technique. Club Mitrale Newsletter, $1988: 1-5$.

24. Van Herwerden L. A., Fraser A. G., Bos E. S. Left ventricular outflow tract obstruction after mitral valve repair assessed with intraoperative echocardiography: non interventional treatment. J Thorac Cardiovasc Surg, 1991, 102: 461-463.

25. Laurent M., Leborgne O., Clement C., Foulgoc J. L., Le Helloco A., Almange C., Leborgne P. Systolic intra-cavitary gradients following aortic valve replacement: an echo-Doppler study. Eur Heart J, 1991, 12: 1098-1106.

26. CANIVET J. L., DAMAS P., LAMY M. Left ventricular geometry of patients with cardiogenic shock after cardiac surgery despite supranormal systolic function. (abstract). Chest, 1995, 108 (3) suppl. : 219 S

27. Aurigemma G., Battista S., Orsinelli D., Sweeney A., Pape L., CUÉNOUd $\mathrm{H}$. Abnormal left ventricular intracavitary flow acceleration in patients undergoing aortic valve replacement for aortic stenosis. A marker for high postoperative morbidity and mortality. Circulation, 1992, 86 (3) : 926-936.

28. Freedom R., Pelech A., Brand A. et al. The progressive nature of subaortic stenosis in congenital heart disease. Int J Cardiol, 1985, 8: 137-143.

29. Newfeld E., Muster A., Paul M., Idriss F., Riker W. Discrete subvalvar aortic stenosis in childhood. Am J Cardiol, 1976, 38: 53-61.

30. Leichter D. A., Suluivan I. D., Gersony W. M. "Acquired" discrete subvalvular aortic stenosis : natural history and hemodynamics. J Am Coll Cardiol, 1989, 14 : 1539-1544.

31. Rosenquist G., Clark E., McAllister H., Bharati S., Edwards J Increased mitral-aortic separation in discrete subaortic stenosis. Circulation, 1979, $60: 70-74$.

32. SHANER R. Malformation of the atrio-ventricular endocardial cushions of the embryo pig and its relation to the defects of the conus and truncus arteriosus. Am J Anat, 1949, 84:431-439.

33. Chor J, Suldivan I. Fixed subaortic stenosis : anatomical spectrum and nature of progression. Br Heart J, 1991, $65: 280-286$.

34. Gewlllio M., Daenen W., Dumoulin M., Van Der Hauwaert L. Rheologic genesis of discrete subvalvular aortic stenosis: Doppler echocardiographic study. JACC, 1992, 19 (4) : 818-824.

35. KIEINERT S., GevA T. Echocardiographic morphometry of the left ventricular outflow tract in fixed subaortic stenosis. $J A C C, 1993$, 22 (5) : 1501-1508.
36. Somerville J. Fixed subaortic stenosis: a frequently misunderstood lesion. Int $J$ Cardiol, 1958, $8: 145-148$.

37. Somervnle J. Aortic stenosis and incompetence. In: Paediatric Cardiology. Anderson R. H., MaCARtney F. J., Shenebourne E. A., TYNAN M. (eds.). London, Churchill Livingstone, 1987 : pp. $987-$ 992.

38. STaRk J., DeLeval M. R. Surgery of the left ventricular outflow tract. In: Surgery for congenital heart defects. 2nd Ed, WB Saunders Co, 1983

39. Konno S., IMAI Y., JdDa Y., Nakajma M., Tatsuno $K$. A new method for prosthetic valve replacement in congenital aortic stenosis associated with hypoplasia of the aortic valve ring. $J$ Thorac Cardiovasc Surg, 1975, 70 : 909-917.

40. VouHe P. R., NEVEUX J. Y. Surgical management of diffuse subaortic stenosis: An integrated approach. Ann Thorac Surg, 1991 $52: 654-662$.

41. Daenen W. J., Vanhove M. A., Gewhlig M. H. Extended aortic root replacement with pulmonary autografts: experience in 14 cases. Ann Thorac Surg, 1995, 60 : S180-S183.

42. SOMERVILLE J. Atrioventricular defects : natural and unnatural history. In : GODMAN M. (ed.). Paediatric cardiology. Edinburgh : Churchill Livingstone, 1980.

43. DeLeon S. Y., Llbawi M. N., Wilson W. R. et al, Surgical options in subaortic stenosis associated with endocardial cushion defects. Ann Thorac Surg, 1991, 52: 1076-1083.

44. Blieden L. C., Randall P. A., Castaneda A. R.; lucas R. V. EDWARDS J. E. The "goose neck" of the endocardial cushion defect : anatomic basis. Chest, 1974, $65: 13-17$.

45. Ebels T., Ho S. Y., Anderson R. H., Mertboom E. T., LugelaAr A. The surgical anatomy of the left ventricular outflow tract in atrioventricular septal defect. Ann Thorac Surg, 1986, 41 : 483-488.

46. Lappen R. S., Muster A. J., IdRiss F. S. et al. Masked subaortic stenosis in ostium primum atrial septal defect: recognition and treatment. Am J Cardiol, 1983, 52 : 336-340.

47. Mace L., Dervanian P., Folliguet T., Grinda J. M., Losay J., NeveuX J. Y. Atrioventricular septal defect with native subaortic stenosis correction by extended valvular detachment. $J J$ Thorac Cardiovasc Surg, 1994, 107 (3) : 943-945.

48. STARR A., Hovaguimian H. Surgical repair of subaortic stenosis in atrioventricular canal defects. J Thorac Cardiovasc Surg, 1994, $108: 373-376$.

49. Kirklin T. W. \& Baratt Boyes B. G. Coarctation of the aorta and interrupted aortic arch. In: Cardiac surgery, 2nd Ed, Churchill Livingstone, 1993.

50. Sell J. E., Jonas R. A., Mayer J. E., Blackstone E. H., Kirklin T. W., CASTANEDA A. R. The results of a surgical program for interrupted aortic arch. J Thorac Cardiovasc Surg, 1988, $96: 864-871$.

51. WILCOX B. R., ANDERSON R. H. Surgical anatomy of the heart: arterial valve and outflow tract malformation. Churchill Livingstone, 1985

52. Freed M. D., Rosenthal A., Plauth W. H. Jr, Nadas A. S. Development of subaortic stenosis after pulmonary artery banding. Circulation, 1973, 47/48 (Suppl 3) : 7.

53. BRADLEY S. M. Late renal cell carcinoma metastasis to the left ventricular outflow tract. Ann Thorac Surg, 1995, 60 (1) : 204206.

54. Nagueh S. F., OMmen S. R., Lakkis N. M., KHllP D., Zoghbi W. A., Schaff H. V., Danielson G. K., QunNones M. A. TaJk A. J, SPENCER W. H. Comparison of ethanol septal reduction therapy with surgical myectomy for thr treatment of hypertrophic obstructive cardiomyopathy. J Am Coll Cardiol, 2001, 38 (6) : 1707-10.

M. A. Radermecker, M.D.

Department of Cardiovascular Surgery

University Hospital of Liège, CHU du Sart-Tilman

4000 Liège, Belgium

Tel. : $32 / 43667163$

Fax : $32 / 43667164$

E-mail : mradermecker@chu.ulg.ac.be 